\title{
Anesthetic Management with Sevoflurane and Oxygen for Orthopedic Surgeries in Racehorses
}

\author{
Minoru OHTA, Kazuomi OKU, Takashi YAMANAKA and Yutaka MIZUNO \\ Racehorse Clinic, Japan Racing Association Miho Training Center, 2500-2 Mikoma, Miho-mura, Inashiki-gun, Ibaraki-ken 300-0493, \\ Japan
}

(Received 28 January 2000/Accepted 26 May 2000)

ABSTRACT. Eighty-five thoroughbred racehorses with various types of fracture were subjected to arthroscopic surgery (44 horses) or internal fixation (41 horses) under sevoflurane anesthesia. The mean end-tidal sevoflurane concentration during anesthesia ranged from 2.5 to $2.8 \% . \mathrm{PaCO}_{2}$ was maintained between 50 and $65 \mathrm{mmHg}$ by controlled ventilation. The mean arterial blood pressure was maintained above $65 \mathrm{mmHg}$ by infusion of dobutamine and fluids, however, heart rate significantly increased with time. Recovery from anesthesia was calm and smooth in almost all cases. No apparent complication was observed during and after anesthesia in all cases. Therefore, sevoflurane anesthesia is considered to be safe and useful for orthopedic surgery in racehorses.

KEY WORDS: orthopedic surgery, racehorse, sevoflurane anesthesia.

J. Vet. Med. Sci. 62(9): 1017-1020, 2000

Sevoflurane is a halogenated, volatile anesthetic with a low blood/gas partition coefficient of 0.6 [18] characterized by rapid induction and recovery. In horses, sevoflurane has been reported to induce similar effects on cardiorespiratory function as isoflurane $[2,9,13]$, and to induce smoother recovery compared with other inhalation anesthetics $[4,9$, 13]. However, reports on anesthetic managements with sevoflurane for equine clinical cases are limited. The purpose of this study was to evaluate the anesthetic management with sevoflurane and oxygen for orthopedic surgery in racehorses.

Eighty-five thoroughbred racehorses with various types of fracture were subjected to arthroscopic surgery (44 horses : Group A) or internal fixation (41 horses : Group F). The mean age and body weight were $3.0 \pm 0.3$ years old and 460 $\pm 31 \mathrm{~kg}$ in Group A and $2.9 \pm 0.5$ years old and $461 \pm 28 \mathrm{~kg}$ in Group F, respectively. The horses of Group A had chip fractures of the carpal bones and those of Group $F$ had simple longitudinal fractures of the proximal phalanx, the third metacarpus, or the third metatarsus. All horses were premedicated with xylazine $(1.0 \mathrm{mg} / \mathrm{kg})$ and induced anesthesia by a rapid injection of $5 \%$ guaifenesin containing thiopental sodium $(2.0 \mathrm{~g} / 1,000 \mathrm{~m} l)$ via a 14 -gauge intravenous catheter. The horses were endotracheally intubated and positioned in dorsal recumbency (Group A) or in lateral recumbency (Group F) on a padded surgical table. Anesthesia was maintained with sevoflurane (Maruishi Pharmaceutical Co., Osaka, Japan) and oxygen using an anesthetic system (MOK 94, Silver Medical Co., Tokyo, Japan) specifically manufactured for large animals. Oxygen flow rate was $10 \mathrm{l} / \mathrm{min}$ for approximately $20 \mathrm{~min}$ after induction, and then reduced to 5 $\mathrm{l} / \mathrm{min}$ for the end of anesthesia. The depth of anesthesia was maintained at the stage that the palpebral reflex and nystagmus had completely disappeared. Ventilation was mechanically controlled to maintain $\mathrm{PaCO}_{2}$ between 50 and 65 $\mathrm{mmHg}$. Lactated Ringer's solution was infused at the rate of 8 to $12 \mathrm{ml} / \mathrm{kg} / \mathrm{hr}$ during anesthesia. Dobutamine was infused to maintain the mean arterial blood pressure (MAP) above 65 $\mathrm{mmHg}$.

End-tidal sevoflurane $\left(E T_{\text {SEVO }}\right.$ ) concentrations were measured by an anesthetic gas monitoring system (Type 1304, Bulel \& Care, Copenhagen, Denmark). Respiratory rate (RR), heart rate (HR), ECG, systolic (SAP), diastolic (DAP), and MAP were recorded by an anesthesia monitoring system (IIP M1166A, Hewlett-Packard, U.S.A). SAP, DAP, and MAP were measured by connecting a catheter placed in the facial artery to a pressure transducer (DX-312, Viggo Spectramed, Tokyo, Japan). Arterial blood samples were collected from the catheter in the facial artery every $15 \mathrm{~min}$. $\mathrm{PaO}_{2}, \mathrm{PaCO}_{2}$, and $\mathrm{pH}$ were immediately analyzed by a blood-gas analyzer (288 Blood Gas system, CIBA-CORNING, Co., Tokyo, Japan).

After the end of anesthesia, the horses were immediately moved to a recovery room and positioned in lateral recumbency. The horses in Group A were not assisted whereas those in Group F were assisted when they tried to rise. During recovery, oxygen was supplied via the endotracheal tube and demand valve until adequate spontaneous respiration was resumed. Twenty cases of Group $F$ were given xylazine (100 mg, i.v.) at the end of anesthesia.

Analysis of variance for multiple groups and repeated measures was used to evaluate the cardiorespiratory data. When significant differences were identified, differences within the group were analyzed by paired $t$-test and those between the groups were analyzed by unpaired $t$-test. A value of $\mathrm{P}<0.05$ was considered as statistically significant. Data were expressed as mean \pm s.d.

Mean values for $\mathrm{ET}_{\mathrm{SEvo}}$ concentration, $\mathrm{RR}, \mathrm{HR}, \mathrm{SAP}$, DAP, and MAP are shown in Table 1 and those for $\mathrm{PaO}_{2}$, $\mathrm{PaCO}_{2}$, and $\mathrm{pH}$ are shown in Table 2. The mean duration of anesthesia was $82 \mathrm{~min}$ in Group A and $107 \mathrm{~min}$ in Group F, respectively.

Induction of anesthesia was smooth in almost all cases and 
Table 1.1. Mean values ( $\pm \mathrm{SD}$ ) of $\mathrm{ET}_{\mathrm{SEvo}}$, respiratory rate (RR), heart rate (HR) and systolic (SAP), mean (MAP) and diastolic (DAP) arterial blood pressures during maintenance of anesthesia in Group A.

\begin{tabular}{|c|c|c|c|c|c|c|c|}
\hline $\begin{array}{l}\text { Time } \\
\text { (min) }\end{array}$ & $\begin{array}{l}\text { No. } \\
\text { (n) }\end{array}$ & $\begin{array}{c}\mathrm{ET}_{\text {SEVO }} \\
(\%)\end{array}$ & $\begin{array}{c}\mathbf{R R} \\
\text { (breaths/min) }\end{array}$ & $\begin{array}{c}\mathrm{HR} \\
\text { (beats/min) }\end{array}$ & $\begin{array}{c}\text { SAP } \\
(\mathrm{mmHg})\end{array}$ & $\begin{array}{c}\text { MAP } \\
(\mathrm{mmHg})\end{array}$ & $\begin{array}{c}\text { DAP } \\
(\mathrm{mmHg}) \\
\end{array}$ \\
\hline 5 & 44 & $1.90 \pm 0.44$ & $6 \pm 2$ & $29 \pm 3^{\mathrm{AB}}$ & $92 \pm 19^{\mathrm{AB}}$ & $77 \pm 10^{A}$ & $58 \pm 14$ \\
\hline 10 & 44 & $2.60 \pm 0.28$ & $6 \pm 2$ & $29 \pm 3^{\wedge \mathrm{B}}$ & $91 \pm 15^{\wedge \mathrm{B}}$ & $63 \pm 12 \mathrm{BC}$ & $51 \pm 13$ \\
\hline 15 & 44 & $2.72 \pm 0.23$ & $6 \pm 2$ & $29 \pm 3^{\mathrm{AB}}$ & $86 \pm 11^{\text {B }}$ & $62 \pm 10$ & $48 \pm 11$ \\
\hline 20 & 44 & $2.73 \pm 0.24$ & $7 \pm 2$ & $27 \pm 3^{\mathrm{B}}$ & $93 \pm 9^{A B}$ & $64 \pm$ & $51 \pm$ \\
\hline 25 & 44 & $2.70 \pm 0.24$ & $7 \pm 2$ & $27 \pm 3^{\text {B }}$ & $97 \pm$ & $66 \pm$ & $52 \pm$ \\
\hline 30 & 44 & $2.71 \pm 0.21$ & $8 \pm 1$ & $28 \pm 3^{\text {в }}$ & $97 \pm$ & $67 \pm$ & $53 \pm$ \\
\hline 35 & 44 & $2.69 \pm 0.26$ & $8 \pm 0$ & $29 \pm 3^{\mathrm{AB}}$ & $99 \pm$ & $68 \pm$ & $53 \pm$ \\
\hline 40 & 44 & $2.64 \pm 0.26$ & $8 \pm 1$ & $30 \pm 3^{\mathrm{ABC}}$ & $100 \pm 10^{A}$ & $68 \pm$ & $54 \pm$ \\
\hline 45 & 44 & $2.61 \pm 0.26$ & $8 \pm 1$ & $31 \pm 4^{\mathrm{ABCD}}$ & $101 \pm 9^{A}$ & $8^{\mathrm{ABC}}$ & $55 \pm$ \\
\hline 50 & 44 & $2.53 \pm 0.24$ & $8 \pm 1$ & $32 \pm 4^{A} C D$ & $99 \pm 11^{\wedge}$ & $69 \pm$ & $55 \pm$ \\
\hline 55 & 44 & $2.54 \pm 0.23$ & $8 \pm 1$ & $33 \pm 4 \quad D$ & $100 \pm 11^{A}$ & $8^{\mathrm{ABC}}$ & $56 \pm$ \\
\hline 60 & 44 & $2.53 \pm 0.23$ & $8 \pm 1$ & $34 \pm 5$ & $100 \pm 11^{\wedge}$ & $71 \pm$ & $57 \pm$ \\
\hline 65 & 44 & $2.53 \pm 0.25$ & $8 \pm 1$ & $35 \pm 5$ & $101 \pm 11^{\Lambda}$ & $71 \pm$ & $58 \pm$ \\
\hline 70 & 44 & $2.53 \pm 0.27$ & $8 \pm 1$ & $35 \pm 6$ & $98 \pm$ & $71 \pm 6^{A B}$ & $58 \pm 7$ \\
\hline $75^{\&}$ & 39 & $2.56 \pm 0.29$ & $8 \pm 2$ & $35 \pm 5$ & $98 \pm$ & $73 \pm$ & $59 \pm 10$ \\
\hline $80^{\$}$ & 28 & $2.56 \pm 0.26$ & $9 \pm 1$ & $37 \pm 5$ & $100 \pm 13$ & $72 \pm$ & $61 \pm 11$ \\
\hline $85^{\&}$ & 18 & $2.55 \pm 0.20$ & $9 \pm 2$ & $40 \pm 6$ & $97 \pm \quad 8$ & $70 \pm$ & $61 \pm 11$ \\
\hline $90^{\&}$ & 12 & $2.55 \pm 0.21$ & $8 \pm 0$ & $40 \pm 4$ & $95 \pm$ & $71 \pm 9$ & $58 \pm 10$ \\
\hline $95 \$$ & 4 & $2.55 \pm 0.07$ & $8 \pm 0$ & $44 \pm 2$ & $100 \pm$ & $71 \pm$ & $59 \pm 3$ \\
\hline $100^{\$}$ & 2 & $2.55 \pm 0.07$ & $8 \pm 0$ & $44 \pm 2$ & $101 \pm 2$ & $72 \pm 2$ & $60 \pm 2$ \\
\hline
\end{tabular}

Table 1.2. Mean values $( \pm \mathrm{SD})$ of $\mathrm{ET}_{\mathrm{Siv}}$, respiratory rate $(\mathrm{RR})$, heart rate $(\mathrm{HR})$ and systolic $(\mathrm{SAP})$, mean (MAP) and diastolic (DAP) arterial blood pressures during maintenance of anesthesia in Group $F$

\begin{tabular}{|c|c|c|c|c|c|c|c|c|c|}
\hline $\begin{array}{l}\text { Time } \\
(\min )\end{array}$ & $\begin{array}{l}\text { No. } \\
\text { (n) }\end{array}$ & $\begin{array}{c}\mathrm{ET}_{\text {SEVo }} \\
(\%)\end{array}$ & $\begin{array}{c}\mathrm{RR} \\
\text { (breaths/min) }\end{array}$ & $\begin{array}{c}\mathrm{HR} \\
\text { (beats } / \mathrm{min} \text { ) }\end{array}$ & $\begin{array}{c}\text { SAP } \\
(\mathrm{mmHg})\end{array}$ & \multicolumn{2}{|l|}{$\begin{array}{c}\mathrm{MAP} \\
(\mathrm{mmHg})\end{array}$} & \multicolumn{2}{|l|}{$\begin{array}{c}\text { DAP } \\
(\mathrm{mmHg})\end{array}$} \\
\hline 5 & 41 & $1.88 \pm 0.39$ & $6 \pm 2$ & $31 \pm 4^{A}$ & $107 \pm 10^{A}$ & $82 \pm 8^{\AA}$ & & $70 \pm 9^{* A}$ & \\
\hline 10 & 41 & $2.58 \pm 0.18$ & $6 \pm 3$ & $30 \pm 4^{A}$ & $99 \pm 8^{A B}$ & $74 \pm 6^{*}$ & & $60 \pm 8^{*}$ & B \\
\hline 15 & 41 & $2.69 \pm 0.14$ & $7 \pm 1$ & $30 \pm 4^{\lambda}$ & $97 \pm 5^{* B}$ & $69 \pm 6$ & B C & $57 \pm 9^{*}$ & B \\
\hline 20 & 41 & $2.70 \pm 0.19$ & $7 \pm 1$ & $30 \pm 5^{\Lambda}$ & $99 \pm 9^{\mathrm{A} \mathrm{B}}$ & $65 \pm 6$ & $\mathrm{c}$ & $56 \pm 8$ & B \\
\hline 25 & 41 & $2.71 \pm 0.21$ & $8 \pm 1$ & $31 \pm 5^{A}$ & $99 \pm 10^{A B}$ & $67 \pm 8$ & $\mathrm{C}$ & $57 \pm 7$ & B \\
\hline 30 & 41 & $2.74 \pm 0.25$ & $8 \pm 0$ & $32 \pm 6^{\wedge \mathrm{B}}$ & $97 \pm 12$ & $69 \pm 8$ & B C & $56 \pm 8$ & B \\
\hline 35 & 41 & $2.72 \pm 0.27$ & $8 \pm 0$ & $32 \pm 6^{\mathrm{ABC}}$ & $96 \pm 12 \quad$ B & $70 \pm 8$ & B C & $55 \pm 7$ & B \\
\hline 40 & 41 & $2.71 \pm 0.26$ & $8 \pm 0$ & $33 \pm 7^{A B C}$ & $96 \pm 13^{\text {в }}$ & $70 \pm 8$ & B C & $55 \pm 7$ & B \\
\hline 45 & 41 & $2.68 \pm 0.25$ & $8 \pm 0$ & $33 \pm 7^{A B C}$ & $98 \pm 11^{A B}$ & $73 \pm 8$ & B & $56 \pm 7$ & B \\
\hline 50 & 41 & $2.64 \pm 0.27$ & $8 \pm 0$ & $34 \pm 6^{\mathrm{ABC}}$ & $98 \pm 11^{A B}$ & $74 \pm 7$ & B & $57 \pm 8$ & B \\
\hline 55 & 41 & $2.62 \pm 0.24$ & $8 \pm 0$ & $35 \pm 7^{\wedge \mathrm{BC}}$ & $98 \pm 9^{\wedge \mathrm{B}}$ & $75 \pm 6$ & B & $58 \pm 6$ & B \\
\hline 60 & 41 & $2.63 \pm 0.23$ & $8 \pm 1$ & $35 \pm 8^{\mathrm{ABC}}$ & $100 \pm 9^{\mathrm{AB}}$ & $75 \pm 7$ & B & $58 \pm 6$ & B \\
\hline 65 & 41 & $2.61 \pm 0.24$ & $8 \pm 1$ & $36 \pm 7^{\mathrm{ABC}}$ & $100 \pm 11^{\mathrm{AB}}$ & $74 \pm 6$ & B & $59 \pm 6$ & в \\
\hline 70 & 41 & $2.59 \pm 0.23$ & $8 \pm 1$ & $36 \pm 7^{\wedge \mathrm{B} C}$ & $100 \pm 11^{\mathrm{AB}}$ & $74 \pm 7$ & B & $59 \pm 7$ & B \\
\hline 75 & 41 & $2.59 \pm 0.23$ & $8 \pm 0$ & $36 \pm 7^{\mathrm{ABC}}$ & $100 \pm 10^{A B}$ & $75 \pm 7$ & B & $59 \pm 6$ & B \\
\hline 80 & 41 & $2.60 \pm 0.23$ & $8 \pm 0$ & $37 \pm 7 \mathrm{BC}$ & $101 \pm 12^{\wedge B}$ & $75 \pm 7$ & B & $60 \pm 7$ & B \\
\hline 85 & 41 & $2.64 \pm 0.23$ & $8 \pm 0$ & $37 \pm 7 \mathrm{BC}$ & $100 \pm 13^{A B}$ & $75 \pm 7$ & B & $61 \pm 9^{A}$ & B \\
\hline 90 & 41 & $2.64 \pm 0.23$ & $8 \pm 0$ & $38 \pm 7$ & $99 \pm 8^{A B}$ & $73 \pm 5$ & B & $59 \pm 5$ & B \\
\hline $95 \S$ & 37 & $2.66 \pm 0.24$ & $8 \pm 1$ & $37 \pm 6$ & $100 \pm 9$ & $74 \pm 5$ & & $60 \pm 6$ & \\
\hline $100 \$$ & 29 & $2.68 \pm 0.25$ & $8 \pm 1$ & $37 \pm 6$ & $100 \pm 10$ & $75 \pm 6$ & & $61 \pm 7$ & \\
\hline $105 \$$ & 25 & $2.68 \pm 0.23$ & $8 \pm 1$ & $40 \pm 8$ & $101 \pm 9$ & $74 \pm 7$ & & $61 \pm 6$ & \\
\hline $110 \$$ & 16 & $2.70 \pm 0.27$ & $8 \pm 2$ & $40 \pm 7$ & $100 \pm 7$ & $77 \pm 5$ & & $63 \pm 5$ & \\
\hline $115 \S$ & 10 & $2.77 \pm 0.30$ & $9 \pm 1$ & $40 \pm 6$ & $101 \pm 9$ & $77 \pm 8$ & & $65 \pm 7$ & \\
\hline $120 \$$ & 7 & $2.72 \pm 0.32$ & $8 \pm 2$ & $42 \pm 5$ & $102 \pm 12$ & $73 \pm 5$ & & $66 \pm 8$ & \\
\hline $125 \$$ & 1 & 2.80 & 8 & 45 & 100 & 75 & & 64 & \\
\hline
\end{tabular}

$\S:$ Times not used in the statistical analysis.

* : Significantly different from Group A.

Data with the same superscript are not significantly different from each other.

the depth of anesthesia reached surgical anesthesia stage within $20 \mathrm{~min}$ after induction in both groups. $\mathrm{ET}_{\mathrm{SEVO}}$ concen- tration were maintained at 2.53 to $2.73 \%$ in Group A and 2.59 to $2.74 \%$ in Group F, respectively, during anesthesia. 
Table 2.1. Mean values $( \pm \mathrm{SD}$ ) of arterial blood gas and $\mathrm{pH}$ analyses during maintenance of anesthesia in Group A

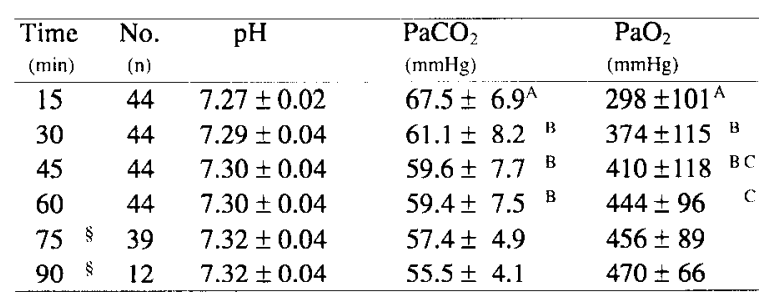

Table 2.2. Mean valucs ( \pm SD) of arterial blood gas and $\mathrm{pH}$ analyses during maintenance of ancsthesia in Group $F$

\begin{tabular}{|c|c|c|c|c|}
\hline $\begin{array}{l}\text { Time } \\
(\min )\end{array}$ & $\begin{array}{l}\text { No. } \\
\text { (n) }\end{array}$ & $\mathrm{pH}$ & $\begin{array}{l}\mathrm{PaCO}_{2} \\
\text { (mmHg) }\end{array}$ & $\begin{array}{l}\mathrm{PaO}_{2} \\
(\mathrm{mmHg})\end{array}$ \\
\hline 15 & 41 & $7.26 \pm 0.04^{\wedge}$ & $67.4 \pm 7.3^{\wedge}$ & $352 \pm 88^{\wedge}$ \\
\hline 30 & 41 & $7.30 \pm 0.04^{\wedge \mathrm{B}}$ & $57.1 \pm 5.1$ & $461 \pm 43$ \\
\hline 45 & 41 & $7.32 \pm 0.04$ & $56.6 \pm 4.8 \quad B C$ & $513 \pm 47^{*}$ \\
\hline 60 & 41 & $7.32 \pm 0.03 \mathrm{BC}$ & $55.3 \pm 4.0 \quad B C$ & $538 \pm 55^{*}$ \\
\hline 75 & 41 & $7.34 \pm 0.02$ & $54.4 \pm 2.2$ & $547 \pm 45$ \\
\hline 90 & $4 !$ & $7.34 \pm 0.02$ & $54.1 \pm 2.7$ & $547 \pm 35$ \\
\hline $105 \leqslant$ & 25 & $7.34 \pm 0.02$ & $55.0 \pm 2.8$ & $551 \pm 40$ \\
\hline $120 \AA$ & 7 & $7.34 \pm 0.01$ & $55.2 \pm 1.9$ & $544 \pm 33$ \\
\hline
\end{tabular}

$\S:$ Times not used in the statistical analysis.

*: Significantly different from Group A.

Data with the same superscript are not significantly different from each other.

Minimum alveolar concentration (MAC) of sevoflurane in horses has been determined to be $2.31 \%$ [1] and 1.2 to 1.3 MAC is necessary to provide sufficient analgesia and immobilization during surgery. In this study, mean $\mathrm{ET}_{\mathrm{SEVO}}$ concentration was maintained somewhat lower than this value in both groups. This is because the duration of anesthesia was short and the premedications were still effective. Since palpebral reflex, nystagmus, or voluntary movement did not appear during surgery, the depth of anesthesia in both groups was considered to be sufficient.

RR decreased immediately after induction and hypercapnia was observed at $15 \mathrm{~min}$ after induction in both groups. Both thiopental sodium and sevoflurane have been reported to depress respiratory function with increase in $\mathrm{PaCO}_{2}[3,9$, 10]. Ventilation/perfusion mismatch caused by hoisting and positioning in dorsal or lateral recumbency also play an important role in the increase in $\mathrm{PaCO}_{2}$. Controlled ventilation is necessary to prevent hypoventilation and to stabilize the uptake of anesthetic gas. On the other hand, increase in intrathoracic pressure caused by controlled ventilation reduces venous return to the heart, resulting in cardiac output decrease $[15,16]$. In this study, to minimize cardiovascular depression, ventilation was controlled at a rate of 6 to 10 breaths/min with a $1: 2$ inspiratory/expiratory ratio and the peak airway pressure was controlled below $25 \mathrm{cmH}_{2} \mathrm{O}$ [15, 17]. Consequently, $\mathrm{PaCO}_{2}$ was maintained between 50 to 65 $\mathrm{mmHg}$, being slightly higher than normal values in awake.

MAP gradually decreased after induction and showed the lowest value at 10 to $20 \mathrm{~min}$ after induction. Sevoflurane is known to depress cardiovascular function dose-dependently
$[2,5]$. Both xylazine and thiopental sodium also have adverse effects on cardiovascular function $[3,6,10]$. In horses, the incidence of postanesthetic complications such as myopathy, lameness, and colitis- $X$ is increased by cardiorespiratory depression during anesthesia $[7,8,12]$. It has been suggested that MAP required to prevent these postanesthetic complications is 65 to $70 \mathrm{mmHg}$ or more $[8,12]$. Therefore, dobutamine and fluids were infused to maintain MAP above 65 $\mathrm{mmHg}$. Total doses of dobutamine infused in Group A and Group F were $0.85 \pm 0.42 \mu \mathrm{g} / \mathrm{kg} / \mathrm{min}$ and $0.72 \pm 0.34 \mu \mathrm{g} / \mathrm{kg} /$ min, respectively. Dobutamine is a synthetic catecholamine which acts directly to increase myocardial contractility by stimulating $\beta_{1}$-adrenergic receptors $[11,14]$ and it is also effective for the maintenance of MAP under sevoflurane anesthesia. Catecholamine release, resulting from the increase in $\mathrm{PaCO}_{2}$, might also stimulate cardiovascular function and increase MAP $[16,17]$.

HR significantly increased with time in both groups. Sevoflurane is reported to have little effect on $\operatorname{HR}[2,5]$ and it is considered that the increase in HR in this study was not due to sevoflurane itself. However, such increase in HR was not observed throughout anesthetic period in Carroll's study [4]. The dose of dobutamine given in this study was about twice as much as that in Carroll's study [4]. Therefore, the increase in HR might mainly be caused by dobutamine because of its positive chronotropic action as well as strong inotropic action [11, 14]. Time-dependent reduction in the effects of premedications might be also responsible for the increase in HR. In this study dobutamine-dependent sinus tachycardia occurred in 4 cases of Group A and 3 cases of Group F, but disappeared soon after stopping the infusion of dobutamine.

Time from the end of anesthesia (the sevoflurane vaporizer being turned off) to appearance of spontaneous respiration, extubation, first movement, first attempt to stand, and standing are shown in Table 3. Recovery from anesthesia is a potentially dangerous period for the horse. In Group A, a few horses attempted to rise before they could support their own weight. However, recovery from anesthesia was calm and smooth with minimal ataxia in almost all cases. To prevent rough recovery, xylazine was administered in 20 cases of Group F. Although the time to standing was prolonged, postmedication with xylazine resulted in subjectively smoother recovery.

In conclusion, sevoflurane provided good maintenance of anesthesia and smooth recovery. Moreover, no apparent complication was observed during and after anesthesia in all cases. Therefore, sevoflurane anesthesia is considered to be safe and useful for orthopedic surgery in racehorses

\section{REFERENCES}

1. Aida, H., Mizuno, Y., Hobo, S., Yoshida, K. and Fujinaga, T. 1994. J. Vet. Med. Sci. 56: 1161-1165.

2. Aida, H., Mizuno, Y., Hobo, S., Yoshida, K. and Fujinaga, T. 1996. Vet. Surg. 25: 164-170.

3. Bennett, R.C., Taylor, P.M., Brearley, J.C., Johnson, C.B. and Luna, S.P. 1998. Vet. Rec. 142: 541-545. 
Table 3. Anesthesia duration and time from sevoflurane off to appearance of spontaneous ventilation, extubation, first movement, first attempt to stand, and standing in horses of Group A, Group F without xylazine, and Group F with xylazine

\begin{tabular}{lrrrr}
\hline & Group A & $\begin{array}{c}\text { Group F } \\
\text { without xylazine }\end{array}$ & $\begin{array}{c}\text { Group } \bar{F} \\
\text { with xylazine }\end{array}$ \\
\hline $\begin{array}{l}\text { Horses }(\mathrm{n}) \\
\text { Anesthesia duration (min) }\end{array}$ & 33 & 20 & 17 \\
Time from sevoflurane off to & $81.9 \pm$ & 9.9 & $106.9 \pm 13.3$ & $107.7 \pm 12.0$ \\
$\quad$ appearance of spontaneous ventilation & $4.3 \pm$ & 3.5 & $6.2 \pm 3.9$ & $4.5 \pm 3.6$ \\
$\quad$ extubation & $10.4 \pm 5.6$ & $12.9 \pm 2.8$ & $10.5 \pm 3.6$ \\
first movement & $13.3 \pm 5.5$ & $20.1 \pm 9.5$ & $15.9 \pm 9.0$ \\
first attempt to stand & $32.1 \pm 12.8$ & $42.3 \pm 9.5$ & $48.0 \pm 8.5$ \\
standing & $37.6 \pm 13.3$ & $43.4 \pm 8.6$ & $49.1 \pm 8.0$ \\
\hline
\end{tabular}

4. Carroll, G.L., Hooper, R.N., Rains, C.B., Martinez, E.A., Matthews, N.S., Hartsfield, S.M. and Beleau, M.H. 1998. Equine Vet. J. 30: 402-407.

5. Ebert, T.J., Harkin, C.P. and Muzi, M. 1995. Anesth. Analg. 81: S11-S22.

6. England, G.C. and Clarke, K.W. 1996. Br. Vet. J. 152: 641-657

7. Flaherty, D., Nolan, A. and Reid, J. 1996. Equine Vet. Educ. 8: 17-22.

8. Grandy, J.L., Steffey, E.P. and Hodgson, D.S. 1987. Am. J. Vet. Res. 48: 192-197.

9. Grosenbaugh, D.A. and Muir, W.W. 1998. Am. J. Vet. Res. 59: 101-106.

10. Hikasa, Y., Takase, K. and Ogasawara, S. 1994. Zentralbl Veterinarmed A 41: 700-708.

11. Holloway, G.A. and Frederikson, E.L. 1974. Anesth. Analg. 53:
616-622.

12. Lindsay, W.A., Robinson, G.M. and Brunson, D.B. 1989. Am.J. Vet. Res. 50: 404-410.

13. Matthews, N.S., Hartsfield, S.M., Mercer, D., Beleau, M.H. and MaCkenthun, A. 1998. Vet. Surg. 27: 480-485.

14. Mills, R.R. and Tuttle, J. 1975. Circ. Res. 36: 185-196.

15. Mizuno, Y., Aida, H., Hara, H. and Fujinaga, T. 1994. J. Vet. Med. Sci. 56: 39-44.

16. Steffey, E.P., Willits, N. and Woliner, M. 1992. Am. J. Vet. Res. 53: $1850-1858$.

17. Wagner, A.E., Bednarski, R.M. and Muir, W.W. 1990. Am. J. Vet. Res. 51: 1922-1929.

18. Wallin, R.F., Regan, B.M., Napoli, M.D. and Stern, I.J. 1975. Anesth. Analg. 54: 758-765. 